\section{Chromosomes decide sex}

Genetics of Sex Differentiation. By Ursula Mittwoch. Pp. xi+253. (Academic (Harcourt Brace Jovanovich): New York and London, June 1973.) $\$ 16.50$.

THAT sex was another example of the transmission of hereditary factors rather than an environmentally controlled duality was probably first postulated by Mendel but was still a pertinent question at the turn of the century. In the companion book, Sex Chromosomes (Academic, London; 1967), Ursula Mittwoch briefly reviewed the early concepts of how sex is determined, which followed the discovery of the sex chromosomes. She dealt in detail with the mechanism in plants and animals, presenting the view that sex determination may be a process not depending on specific differences of protein production.

The present book is a general and useful introduction to the subject of sex development and its control especially in vertebrates and amplifies this concept. It is important, at this stage, to distinguish between sex determination (the primary event that decides on the type of gonad that an embryo makes) and sex differentiation (the subsequent effects of the gonad on embryogenesis of the other sex structures). The aim of the book is to give substance to the idea that sex determination results from an epigenetic control that primarily resides in whole chromosomes or chromosome segments. These, because they are visibly different, are assumed to have an effect on development "which cannot be accounted for in terms of genes". In other words the suggestion is that sex chromosomes determine sex by functioning as larger units rather than through the action of individual genes: this is the first part of the hypothesis. For its second part the author turns to non-genetic DNA, its redundancy, variation and function and to the view that sex chromosomes may control sex determination by affecting differentially the rates at which cells divide and grow during embryogenesis.

The thesis that Mittwoch presents is contrasted with other hypotheses involving discrete genic determinants, as the mainspring for gonadal differentiation, and she marshals various lines of support for it. Examples are taken from the effect of heterochromatic B chromosomes on mitotic rates in plants, the effect of $\mathrm{X}$ chromosomes on the mitotic cycle of human cells in vitro, the effect of growth rates on embryonic differentiation, particularly the analysis of transdetermination of Drosophila imaginal disks, and finally the effect of the various environmental influences on embryonic differentiation. Indeed, the bulk of the first six of the seven chapters of the book is an introduction to the thesis developed in the final chapter.

Irrespective of whether the hypothesis which this book discusses will ultimately turn out to be right or wrong, it is important that attention has been drawn to it. Experiments of nature should be scrutinised and experiments should be devised to see if they falsify the idea, but until then it should rank with the discrete gene hypotheses of sex determination.

Paul E. Polani

\section{Insects of Europe}

A Field Guide to the Insects of Britain and Northern Europe. By Michael Chinery. Pp. 352. 60 plates. (Collins: London, November 1973.) £2.95.

THIs latest addition to the Collins' Field Guide series follows their recent pattern of including Europe, in this case Europe north of the Alps. But anyone expecting to identify any insect encountered, either in this country or while holidaying on the Continent, will be sadly disappointed. This field guide only claims to enable people with no previous knowledge of the subject to first make sure that what they have found is an insect, and second to place it in the correct order and either the appropriate superfamily or family. For further identification to species a fairly extensive bibliography is provided, although some may be recognised from the superb colour plates. Those depicting lepidopterous larvae are, however, rather garish and are irritatingly interleaved with the glossary.

The glossary surprisingly omits the only obvious competitor, The Oxford Book of Insects. Although this new guide does not contain the comprehensive coverage of butterflies and dragonflies, it has advantages over the other in containing simplified keys, well illustrated with thumbnail sketches. The author admits that these ignore the 'oddman-out' but they are nonetheless very valuable.

There is an excellent general introduction to entomology containing essential details of anatomy and biology, with notes on collecting and preserving insects. Unfortunately the Code for Insect Collecting is printed on the dust jacket which may become separated from the book. There is a concise chapter on classification and taxonomy and a list of entomological suppliers. It is unfortunate that the Lepidoptera section of the revised Kloet and Hincks could not be used, but the use of archaic Psocoptera nomenclature is less forgivable. Little content would have been lost by covering only British insects, although I believe there is a similar need for such a guide on the Continent. The book will sell on first impressions alone, and is extremely good value. R. COLIN Welch

\section{Theory of athletics}

The Mechanics of Athletics. By G. Dyson. Pp. 240. (University of London: London, September 1973.) Boards £3.30; paper $£ 2.20$.

THIS book, by the Director of Physical Education at Winchester, formerly Chief National Coach to the Amateur Athletic Association, is one that every athlete wishing to add to his skill should continually study. Mr Dyson has vast experience of athletics and coaching, and makes clear at the outset his creed that the theoretical understanding of what one is supposed to be doing is the key to improvement. "Those enamoured of practice without science [theory] are like a pilot without rudder or compass, never certain where he is going", he quotes (from Leonardo da Vinci). But he well understands that the theory must be allowed to sink in and become so much part and parcel of the method of the performer that he comes to do the right things automatically, and it is the task of a coach to induct such theory with skilful application. This of course holds for most if not all instruction: the existing level of a pupil's state of understanding and attainment must be assessed and the philosophic pill gilded accordingly.

After first lucidly expounding what is needed to be known for his purposes about motion and force, and about rotatory motion with its less obvious centripetal and gyroscopic consequences, Mr Dyson takes his readers through everything that he has found to be essential in comprehending the correct principles of running, hurdling, jumping (high and long), pole vaulting, shot putting, and throwing the hammer, discus, and javelin. No great prior knowledge of mechanics is required from the reader. Any athlete who has come to a steady state of achievement, yet nevertheless feels he ought to be able to do better, may well find the secret to his making fresh progress in the relevant chapters of this book. It has seen five previous editions, been translated into several languages including Japanese (who mean business in the sporting world, be it noted), and not surprisingly is required reading in many universities.

It is hard to know how many readers of Nature may also be interested in athletics, but if they are not themselves, their children or friends may be, and whether or not these have access to coaching at high level, this book could well make an admirable scientific gift of permanent value that would do much to add to their enjoyment of athletics both through greater appreciation of the fundamentals and improvement of their own performance.

R. A. Lyttleton 